\title{
SIELKUNDE EN SIELSORG
}

By baie mense bestaan daar nog vyandigheid teen die sielkunde. Ander staan heeltemaal onverskillig daarteenoor. Hierdie houdings mag moontlik uit die weg geruim word wanneer beide dissiplines, naamlik sielkunde sowel as sielsorg, in die regte perspektief gesien word.

Dit moet egter duidelik verstaan word dat sielkunde nie sielsorg is en sielsorg nie sielkunde is nie. Elk het sy eie werkopdrag en vakterrein.

Die sielsorger kan egter vrugbaar gebruik maak van die sielkundige beginsels en -waarhede. Dieselfde geld vir die gelowige sielkundige, en meer bepaald vir die gelowige psigo-terapeut.

Dit is die aangewese weg om eers kortliks in te gaan op die terrein en doel van sielkunde en sielsorg.

\section{A. Sielkunde}

Hoewel baie omskrywings van die term ,sielkunde" die lig gesien het, is daar tog geen aanneembare enkel-sin definisie nie. Dog oor die algemeen word gesê dat sielkunde 'n empiriese wetenskap is wat sig besig hou met die bestudering van bewussynsverskynsels en die objektiewe gedrag van die mens. (Harriman, 1947, p. 274; van Rensburg, 1950, p. 3)

In die studie van gedrag word besondere aandag gegee aan die vorming van persoonlikheid, sowel as aan die aard van drange en emosies as die bronne en bepalers van aangepaste sowel as nie-aangepaste gedrag. Die mens word ook bestudeer in sy ontwikkeling as fisiologiese en psigologiese entiteit vanaf ontvangenis tot by die dood, as mede teen die agtergrond van sy besondere persoonlikheid, omgewingsomstandighede en 
die kultuur waaraan hy behoort, $\mathrm{Al}$ hierdie faktore is mede verantwoordelik vir sy gedrag. Gevolglik lê dit ook op die weg van die sielkunde om 'n deeglike studie te maak van die simptome wat elke geestes- en gedragsversteuring vergesel. Sodoende sien en beoordeel die sielkundige 'n persoon in sy aangepaste sowel as sy wanaangepaste gedrag in terme van die psigodinamiese faktore wat in hom werksaam is, sowel as in terme van sy omgewingsomstandighede wat van buite af sy gedrag beinnloed.

\section{B. Sielsorg}

Thurneysen (1946) sowel as Bovet (1952, p.7) wat hom op Thurneysen beroep, sien sielsorg in die Kerk as die toespitsing van Gods Woord op die enkeling.

Omdat dit die toespitsing van Gods Woord op die enkeling is, word hieruit afgelei dat die sielsorg in die gespreksituasie plaasvind en dat die voorwerp van die sielsorg in daardie gesprek deur die sielsorger met die Woord van God bedien word. Die sielsorggesprek is egter nie dieselfde as die prediking tot die gemeente nie en daarom nie 'n miniatuur erediens nie.

Hier moet egter nie die afleiding gemaak word dat die kerugma of die goddelike Boodskap uit die sielsorggesprek verdwyn het nie. Dit is juis die kerugma wat aan die sielsorg sy wesenlike inhoud en rigting gee, want dit is die altyd lewende en die altyd werkende in die gemeente en in die gesprekke wat in die gemeente gevoer word. Hoewel dit soms voorkom asof die kerugma uit die sielsorggesprekke verdwyn het, het dit in werklikheid net daar in verdwyn.

Dit is die taak van die sielsorger om die mens in sy afdwaling, onsekerheid en angs, maar ook in sy weerbarstigheid en vyandigheid wat voortvloei uit sy innerlike konflik, met 'n woord uit Gods Woord heen te wys na Jesus, die sondaarsvriend. Kragtens hierdie sielsorglike heenwysing na die Verlosser van die sondaar, kan die beangste en onsekere mens rus vind by Jesus.

In elke individuele noodsituasie moet die sielsorger simpatiek en biddend luister na sy medemens in die nood. Dan moet hy die voorwerp van sy sielsorg versorg met 'n woord. Dit mag egter nie sy eie woord wees waarmee hy moraliseer, veroordeel of vryspreek nie. Maar dit moet 'n woord wees wat hy afgeluister het van die Evangelie en afgebid het van die Heilige Gees.

In die sielsorggesprek staan die sielsorger tussen die mens en die Woord van God, waarvan hy slegs die bedienaar is aan die beangste, onveiligvoelende en met skuldbelaaide mens.

Dit spreek vanself dat die sielsorger in die eerste plek 'n grondige kennis van Gods Woord moet besit - dit nie alleen ken nie, maar dit 
ook glo, homself daardeur aangespreek, gelei en getroos voel, sodat hy dit oortuigend en effektief kan oordra aan die mens wat aan sy sielsorg toevertrou is.

Aan die anderkant is dit ook duidelik dat die sielsorger die voorwerp van sy sielsorg, nl. die mens sal ken in sy geestes-aktiwiteite sowel as in sy openlike gedrag, in al sy ontwikkelingstadiums en in al die nuanses wat sy normale sowel as abnormale gedrag kenmerk.

\section{Geen Verband}

Op die vraag of daar ' $n$ verband tussen sielkunde en sielsorg bestaan, moet ontkennend geantwoord word. Dit is twee onderskeie vakgebiede, elk met sy eie opdrag. Dit kan egter nie ontken word dat die een die ander met vrug in sy eie taakverrigting kan betrek nie.

\section{Hulpavetenskap}

Die sielkunde as sodanig, of die sielkundige kennis van die sielsorger, moet nooit die riglyne van die sielsorg bepaal nie, want dan loop die sielsorg gevaar om te ontaard in 'n sosiale evangelie, maar dit moet bepaal word deur die Woord van God. Die sielkunde word slegs aangewend as hulpwetenskap om die sielsorgvoorwerp te peil en te benader. Aan die hand van sy sielkundige kennis doen die sielsorger die nodige verkenningswerk voordat hy die Boodskap van die Meester aflewer. Tereg sê Thurneysen (1946, p.174) „Das Ansprechen des Menschen im Seelsorgegespräch setzt Menscherkenntnis voraus: Die Seelsorge bedarf darum der Psychologie als einer Hilfswissenschaft, die der Erforschung der inneren Natur des Menschen dient, und die diese Kenntnis vermitteln kann."

Dit geld onder normale omstandighede. Hoeveel te meer is dit nie die geval t.o.v. die sielsorg aan oues van dae, krankes en psigies gesteurdes nie?

\section{Sielsorg aan Psigies Afurkendes}

Die vraag ontstaan of sielsorg gedoen moet word aan ' $n$ persoon wat aan 'n akute sielkundige versteuring ly. Indien wel, op watter wyse.

Op grond van die bestaande kennis oor die psigodinamika van die neurose, is dit bekend dat ' $n$ neurose ontstaan uit 'n konflik tussen twee of meer botsende behoeftes en strewinge. Uit hierdie konflik wat die persoon nie by magte is om op ' $n$ toereikende wyse die hoof te lied en op te los nie, groei frustrasie, angs en vyandigheid. Dit plaas die persoon naderhand in 'n bose kringloop, waaruit hyself nie meer kan ontkom sonder sielkundige hulp nie. Sy afwykende gedrag is dan eintlik sy tevergeefse en wanaangepaste pogings om aan sy konflik en angs te ontkom. Daar deur probeer hy ontvlug aan sy onvermoë om die lewensstryd te stry. 
Volgens Carp (1947, p. 4) bestaan sy afwyking eintlik uit fiktiewe waardes wat hy vir homself stel, en waardeur hy die indruk probeer skep dat hy tog die lewensstryd op 'n aangepaste wyse probeer stry. In hierdie konflikworsteling van die neurotikus neem onvermoë vir hom dan die vorm aan van skuld.

Wanneer die sielsorger nou die neuroot nader, moet hy besef dat hy te doen het met 'n persoon wat aan patologiese angs onderwerp is. $\mathrm{Hy}$ worstel met 'n gewaande skuldbesef wat hy nie by magte is om te hanteer nie. Op grond van die sielsorger se sielkundige kennis sal hy bedag wees op die reaksiepatrone wat van so 'n persoon verwag kan word. Gevolglik sal dit vir hom nie eienaardig, teleurstellend of skokkend wees nie.

Die persoon mag op 'n onwaaragtige wyse sy skuld bely, en dit selfs by herhaling doen. Gevolglik kan hy 'n hartgrondige bekering veins. Hierdeur kan die sielsorger maklik onder die verkeerde indruk kom dat hy suksesvol was in sy sielsorg, terwyl dit in werklikheid maar net die neurotiese toestand van die persoon vererger het.

Dit mag ook gebeur dat die sielsorger teen 'n muur van vyandigheid en onverskilligheid bots. Dit kan maklik as onbekeerdheid bestempel word. Dit kan die sielsorger laat twyfel aan die waarde van sy sielsorg of hy kan hom miskien verkeerdelik wend tot tugmaatreëls.

Hieruit mag die afleiding nie gemaak word dat die sielsorg nie moontlik is nie, of miskien ook nie van soveel waarde is, wanneer die sielkunde nie daar by gesleep word nie. Dit is verre van waar, want alle dinge is moontlik by God en geen geval is vir Hom te ver gevorder nie. Daar is gevalle bekend waar akute neuroses genees is alleen as gevolg van die sielsorg wat daar toegepas is. Tog is dit beter om nie net op die wonders te wag en te reken nie, maar ook dankbaar gebruik te maak van elke middel wat God die mens in die hand lê. Dié gevalle is ook bekend waar verligting en genesing van die psigiese afwryking slegs verkry kon word deur die toepassing van psigo-terapeutiese behandeling.

Indien die sielsorger die sielkunde en die psigo-terapie as bondgenoot en hulpwetenskap benut, kan die psigies-afwykende gevalle onderken word en met wetenskaplik-terapeutiese metodes behandel word. Met die sielkundige behandeling word die wond skoongemaak en deur die sielsorger word die salf van die Evangelie op die wond geplaas.

\section{Noodsaaklikheid vir Sielkundige Kennis}

Dit is bekend dat die bevolking van die land snel toeneem. Hand aan hand hiermee groei die getal groot stede en vinnig ontwikkelende industriële gebiede. Dit skep omgewingsituasies wat vrugivaar kan wees vir die ontwikkeling van persoonlikheids- en gedragsafwykings. In die stadsgemeentes en in besonder in nywerheidsgebiede, is dit onvermydelik dat die sielsorger in die uitvoering van sy taak met hierdie wirwar van 
menseverhoudings en letselgewende situasies te doen sal kry. Dit behoef eintlik geen betoog dat 'n grondige kennis van die sielkunde een van die nuttigste instrumente in die hand van die sielsorger is nie.

Hoewel die mens op alle terreine groot vooruitgang maak en steeds groter hoogtes bereik, voel hy hom tog aan die anderkant bedreig, kwesbaar en eensaam. Hy is nie net die slagoffer van sy eie innerlike konflikte nie, maar sedert Wêreldoorlog II het hy ook in eksistensiële nood en onsekerheid verval. Die mens word al meer bewus van 'n angs wat die glans en glorie van die lewe laat vervaag, want die onrusbarende wete van 'n „NIKS" en die relatiewe aard van alles het tot hom deurgedring. Carp (1947, p. 3 en 4)sê dat die mens besorg geword het oor sy eie bestaan. $\mathrm{Hy}$ is nie net besorg oor sy EK-BESTAAN nie, maar ook oor die regverdiging van sy bestaan. Hy ervaar op grond van sy onvermoë tot aanpassing, die angs dat hy alleen en vereensaam in die lewe sal staan. Dit omsluit die probleem van te wees of nie te wees nie.

Veral die moderne stedeling, wat in velerlei opsigte na 'n massamens lyk, is dan ook, oor die algemeen genome, 'n eensame mens. Die stadslewe waardeur hierdie mens geskep word veroorsaak 'n proses van atomisasie. Die gesin word opgebreek in los atome waardeur die saambindende gesinsverband verloor word. Mense word dan losstaande van mekaar, eensaam, op sigself aangewese en daarom beangs en onseker. Dit bring anonimiteit mee. In die groot, vir mekaar onbekende en onpersoonlike massa, word die eensame en alleenstaande individu ook naamloos, onbekend en gevolglik onbemind vir die ander in die massa. Dit is 'n vrughare teelaarde vir anomie. In die massa word die eis van die norm en die wet, en so ook van die publieke opinie veronagsaam. Die een het niks oor die ander te sê nie.

Dit is vanselfsprekend dat die kind wat onder sulke omstandighede opgroei, uiteenlopende invloede ondergaan, botsende standpunte en houdings waarneem en verwerk. Die moontlikheid is groot dat dit die integriteit van sy persoonlikheid kan skaad en dat dit kan aanleiding gee tot aanpassingsprobleme.

Temidde van die eksistensiële nood en angs met die daarmee gepaardgaande geestesverwarring, lyk dit so dikwels of die stem van die Evangeliedienaar ' $n$ nouliks hoorbare klankie geword het. Dikwels voel die sielsorger hom magteloos wanneer hy met 'n persoon wat dergelike probleme het, gekonfronteer word, want die BOODSKAP van die sielsorger word blykbaar as van minder belang beskou.

Die sielkundige probleme kan in wye kategorieë saamgevat word as Psigoses en Neuroses, Psigopatie, en Swaksinnigheid. As onderdele hiervan kry die predikant veral te doen met akoholisme, seksuele afwykings, karakter afwykings, kriminele geneigdheid, lae moraal, skuldgevoelens, sosiale konflikte, minderwaardigheidsgevoelens met die gevolglike kompensasie-reaksies, ens. 
Die spreekkamers van geneeshere word druk besoek deur mense wat gebuk gaan onder die fisiese simptome van 'n geesteskonflik. Outler $(1959$, p. 13) wys op die konklusie van Fishbein in Hygeia (1949) dat die helfte van die V.S.A. se bevolking neuroties is en 'n derde psigoterapeutiese behandeling nodig het. Oor die toestand in die Republiek van Suid-Afrika is geen offisiële statistieke beskikbaar nie. 'n Gesaghebbende psigiater is egter van mening dat die konklusie van Fishbein nie buite verhouding is nie, en dat dit min of meer ook die persentasie in SuidAfrika sal wees.

Daar is talle mense met sielkundige probleme wat nooit onder die aandag van ' $n$ medikus kom nie. Tog ontmoet die predikant hulle daagliks as sosiaal-wanaangepastes, patologiese leuenaars, kleptomane, kwerilante, aggressiewe onrusstokers, jeugmisdadigers, seksperverte, alkoholiste; as mense wat uiterlik baie opgeruimd en grappig is, maar wat deur daardie oppervlakkige vrolikheid 'n dieper pyn wil wegsteek; persone wat trag om 'n sentimentele, maar oppervlakkige godsdienstigheid te gebruik as 'n dun, maar vir die kenner deurskynende, vernislagie oor 'n siek persoonlikheid wat huiwer in sy angs; intellektuele onverskilliges wat aan alles twyfel en alles wil verwerp net omdat dit vir hulle die geleentheid skep om ,,anders" te wees en so te kompenseer vir 'n wankelende persoonlikheid; foutvinders wat steeds met die vinger wys, kritiseer en beskuldig en dan oorgaan tot opswepery, terwyl dit die handelwyse is van iemand wat gebuk gaan onder 'n skuldgevoel en graag daarvan ontslae wil raak deur dit op ander mense en liggame te projekteer - gewoonlik op die predikant, wat weer vir hom die verteenwoordiger van die kerk is en met wie hy dan uiteindelik die kerk identifiseer en gevolglik alle kerke en alle predikante oorlog aansê.

Hierdie mense is die voorwerpe van die sielsorger se sorg. Sorg in tweërlei sin, want hulle moet nie slegs geestelik versorg word nie, maar hulle verskaf besorgheid omdat hulle die sorg aan hulle met groot onverskilligheid bejeën. Meer nog, omdat sommige die sorg van die sielsorger dikwels bemoeilik en selfs onmoontlik maak deur nie die hulp van die sielsorger op te soek nie, maar na die regsgeleerde en medikus te gaan en in baie gevalle selfs na die kwaksalwer en die toordokter.

\section{Pastorale Sielkunde}

Wanneer die sielsorg (cura animarum) saam met Trillhaas (1950, p. 69, 70) gesien word as die „bekommernis” oor die ,,deel van die mens wat van hoëre waarde is", moet dit met die grootste nougesetheid en takt deur die predikant behartig word. Dit is voor die handliggend dat die sielsorger hom dan, met die oog op sy groot verantwoordelikheid, deur elke moontlike hulpwetenskap sal laat bedien, in besonder deur die pastorale sielkunde.

Die verskil tussen die godsdienspsigologie en die pastorale psigologie is daarin geleë dat die godsdienspsigologie trag om die religieuse gevoelens by die enkeling of die groep te omskryf en te verklaar, terwyl die pastorale 
sielkunde beoog om die herder psigologiese steun te bied in sy herderlike of pastorale arbeid. Van den Berg (p. 39) beskryf dit as volg: „Deze wetenschap omvat de leer van de vormen van zamenzijn, de leer van de gesprek en van de pastorale gesprek, de psychologie van de huwelijk en de huwelijksmoeilikheden, de beschrijving van de levensloop van geboorte tot graf, de leer van het ziekbed, het sterfbed, het huisbezoek en het spreekuur thuis, de leer van de psychische afwijkingen: neurosen en psychosen, de leer van psychotherapie en zielzorg, enz."

Die Nederlandse psigiater Dr. B.Chr. Hamer (1952, p. 7) wys met erns op die noodsaaklikheid daarvan dat die predikant psigologiese insig sal hê teneinde 'n goeie instrument te wees. Die regte leiding kan nie gegee word as die voorwerp van sielsorg nie reg begryp word nie; en indien iemand nie begryp word nie, keer hy hom baie maklik van die sielsorger af. Indien dit vir die "normale mense" geld, hoeveel te meer is dit nie waar van die psigies-afwykendes nie? „,Ook zij worden geplaatst op de weg van de zielzorger. En daar staan zij dan met hun bizondere vragen, hun afwijkende gedachten. Ze komen bij de zielzorger met hun schuldgevoelens, die echter zondewaandenkbeelden zijn.

Wee hen, als deze niet als ziekelijk, als afwijkend door de zielzorger worden herkend. Als deze er op ingaat, als waren deze gedachten niet ontsproten aan een ziekte geest," aldus Hamer.

Bovet (a.w.p. 5) sluit baie nou hierby aan wanneer hy sê: „De dagelijkse ervaring toont echter, dat de zielzorg vaak daardoor zijn doel niet bereikt dat het den theoloog (en in noch sterker mate den leek) ontbreekt aan voldoende kennis van de mens en zijn wegen voor God, zodat zijn woorden den mensch niet raken, ook als zij wel degelijk uit de goede bron komen. Aan de andere kant ontbreekt het den dokter of psychiater meestal daaraan, dat zijn woorden uit de ware bron komen, zodat hij de hulpzoekende mensch alleen uit eigen kracht tracht te helpen. Hij gelijkt daarmede op een brandweerman, die de haard van de vuur wel heeft ontdekt, maar wiens slang niet onder drukt staat; terwijl de theoloog een ferme straal water op het brandende huis richt, maar van veraf, zodat de vuurhaard niet bereikt wordt."

Pretoria-Noord

S. J. PRINS.

Lys van Geraadpleegde Werke

1) Bovet, Th. (1952): Practische Zielzorg, Boekencentrum N.V. s'Gravenhage.

2) Carp, E. A. D. E. (1947): De Neurosen, Scheltema en Holkema, Amsterdam.

3) Hamer, B. Chr. (1952): Zielzorg en Psychiatrie. J. H. Kok. Kamren.

4) Harriman, P. L. (1947): The New Dictionary of Psychology. Phylosophical Library. New York.

b) Outler, A. C. (1959): Psychotherapie en Evangelieverkondiging. Boekencentrum. S'Gravenhage.

-) Thurneysen, E. (1946): Evangel. Verlag. Zollikon.

7) Trillhaas, Wolfgang. (1950): Der Dienst der Kirche Am Menschen. Chr. Kaiser Verlag. München.

s) Van den Berg, J. H. Kroniek der Psychologie.

-) Van Rensburg, J. A. J. (1950): Sielkunde. Unie Volkspers Bpk., Kaapstad. 